\title{
Mortality in severely injured elderly patients: a retrospective analysis of a German level 1 trauma center (2002-2011)
}

\author{
Carsten Schoeneberg ${ }^{1 *}$, Thomas Probst ${ }^{2}$, Marc Schilling ${ }^{1}$, Alexander Wegner ${ }^{1}$, Bjoern Hussmann ${ }^{1}$ \\ and Sven Lendemans ${ }^{1}$
}

\begin{abstract}
Background: Demographic change is expected to result in an increase in cases of severely injured elderly patients. To determine special considerations in treatment and outcome, patients aged 75 years and older were studied.

Methods: All patients in the included age group with an Injury Severity Score (ISS) $\geq 16$ upon primary admission to hospital between July 2002 and December 2011 were included in this mortality analysis. The data used for this study was gained partly from data submitted to the German Trauma Register and partly from patients' hospital records. A comparison between survivors and decedents was performed, as well as age-adjusted and ISS-adjusted analyses. The odds ratio and relative risk were used to determine predictors for mortality.

Results: One-hundred eight patients met the inclusion criteria. The overall mortality proportion was $57.4 \%$. The decedents were more severely injured (ISS 26 vs. 20, p < 0.001) and suffered more severe head traumas (GCS 4 vs. $12, p<0.001$; AIS head 5 vs. $4, p=0.006$ ). No differences were found in vital parameters measured at the accident scene or trauma room. Decedents had deranged coagulation with a prolonged PTT (41.1 sec vs. $27.6 \mathrm{sec}, \mathrm{P}=0.008$ ) and reduced prothrombin ratio (66.5\% vs. $82.8 \%, p=0.016)$.

Only $17.1 \%$ of patients presenting an ISS $>25$ survived, suggesting that an injury of such severity is hardly survivable in the subject age group.

Predictors for mortality were: ISS $>25$, GCS $<9$, PTT $>32.4$ seconds, prothrombin ratio $<70 \%$, AIS head $>3$, and $\mathrm{Hb}<12 \mathrm{~g} / \mathrm{dl}$.

Conclusions: The treatment of severely injured elderly patients is challenging. The most common cause of accident is falling from less than $3 \mathrm{~m}$ with head injuries being determinant. We identified deranged coagulopathy as an important predictor for mortality, suggesting rapid normalization of coagulation might be a key to reducing mortality.
\end{abstract}

Keywords: Trauma, Mortality rate, Elderly patients, Severely injured

\section{Background}

Coping with an increasingly aged population is a challenge for healthcare providers all over the world. In 2011, 21\% of the German population was aged more than 65 years, compared to $15 \%$ in 1990 . No other country in the European Union has such a high rate of elderly [1]. This demographic trend is not only a challenge for internists

\footnotetext{
* Correspondence: carsten.schoeneberg@uk-essen.de

'Department of Trauma Surgery, University Hospital Essen, University

Duisburg-Essen, Hufelandstraße 55, Essen 45147, Germany

Full list of author information is available at the end of the article
}

but for all physicians involved in the treatment of elderly trauma patients.

In an American study, the mortality rate of elderly trauma patients increased 3- to 5-fold after adjusting for injury severity [2]. Age is also described as a risk factor for mortality after trauma [3]. Shifflette et al. suggested that all patients aged more than 60 years with multiple injuries and/or significant mechanisms of injury should be transferred to a level 1 trauma center. They found a three-fold increase in morbidity and a five-fold increase in mortality in elderly patients with an ISS between 0 and $15[4]$.

\section{Biomed Central}

(c) 2014 Schoeneberg et al.; licensee BioMed Central Ltd. This is an Open Access article distributed under the terms of the Creative Commons Attribution License (http://creativecommons.org/licenses/by/4.0), which permits unrestricted use, distribution, and reproduction in any medium, provided the original work is properly credited. The Creative Commons Public Domain Dedication waiver (http://creativecommons.org/publicdomain/zero/1.0/) applies to the data made available in this article, unless otherwise stated. 
Elderly trauma patients have been found to require a greater amount of hospital resources compared to younger patients $[5,6]$. Those with an ISS $>30$ required less time spend in the intensive care unit (ICU) as a result of increased mortality [5].

In an Australian study, the rate of severe trauma to older patients increased by nearly $5 \%$ per year, with one third of all trauma admissions being elderly patients [7].

Elderly patients often present comorbid conditions, concomitant medication (especially anticoagulation medication), and lower physiologic reserve compared to younger trauma patients. These factors reduce their ability to respond to aggressive trauma resuscitation, and injury impact is greater compared to younger patients [8]. Concomitant medication has been shown to frequently alter the hemodynamic response to shock [9], and, because of the absence of hypotension and tachycardia, injury severity and response to resuscitation could be underestimated [10,11].

To anticipate predicted demographic changes and to address an underrepresentation of the oldest patients in the literature, the aim of this study was to determine special considerations in treatment and outcome in patients aged greater than 75 years.

\section{Material and methods}

\section{General information}

This study analyzed the data of a level 1 university-based trauma center in Germany. Serving the catchment area of the Ruhr district with approximately 5.1 million habitants, it is one of the largest trauma centers in Germany. There are four level 1 trauma centers in the Ruhr district and the emergency medical system is mostly ground based, though air transportation via helicopter is available as well. For our hospital, the rate of helicopter ambulance is approximately $11 \%$.

The data used in this study was collected prospectively for the national trauma registry, called the Trauma Registry of the German Society for Trauma Surgery (DGU). The data from the Trauma Registry of the DGU has received full approval from the Ethics Committee of the University of Witten/Herdecke in Cologne, Germany. Because the trauma registry of the DGU is an anonymous register, the Institution Review Board waived the need for patient consent. Additionally, the patients' clinical records were analyzed. For this analysis we received full approval from the Ethics Committee of the medical faculty of the University Duisburg-Essen in Essen, Germany.

\section{Patients}

Inclusion and exclusion criteria are shown in Table 1.

Scales, general patient information, laboratory test values, and intervention data were collected for each patient as follows. Scales: Injury Severity Score (ISS) [12];
Table 1 Inclusion and exclusion criteria applied in this study

\begin{tabular}{cc}
\hline Inclusion criteria & Exclusion criteria \\
\hline Primary admission to the hospital & Transfer from other hospital \\
\hline Activation of the trauma team & No activation of the trauma team \\
\hline ISS $\geq 16$ & ISS $<16$ \\
\hline$\geq 76$ years of age & $<76$ years of age \\
\hline Admission occurred between & \\
July 2002 and December 2011 & \\
\hline
\end{tabular}

Abbreviated Injury Scale (AIS); New ISS [13]; Glasgow Coma Scale (GCS) [14]; Revised Trauma Score (RTS) [15]; Revised Injury Severity Classification (RISC) [16]; and Trauma and Injury Severity Score (TRISS).

General patient information: Age; sex; ASA score; systolic blood pressure at the accident scene and at admission; heart rate at the accident scene and at admission; oxygen saturation at the accident scene and at admission; length of ICU stay; length of hospital stay; count of performed surgeries; administered fluid volume; proportion of multi-organ failure (MOF); proportion of sepsis; and type of injury (penetrating vs. blunt).

Laboratory test values: First hemoglobin $(\mathrm{Hb})$ value; initial number of platelets; partial Thromboplastin time (PTT); Prothrombin time; base excess; and lactate.

Length of analyzed periods: Time from admission to cranial computed tomography (CCT); time from admission to whole-body CT; time in trauma room; time from admission to operating room; and preclinical rescue time (time from arriving at the accident scene to admission in hospital).

Interventions: Intubation, resuscitation, and thoracic drainage by emergency physician at the accident scene and intubation, cardio-pulmonary resuscitation, and thoracic drainage in trauma room.

To allow age-adjusted analysis, the patients were divided into age groups as follows: 76-80 years, 81-85, 86-90, and $>90$ years of age.

Similarly, patients were grouped by ISS: ISS 16-25, 26-35, 36-45, and $>45$.

To determine the difference between decedents and survivors, odds ratios and relative risks with $95 \%$ confidence

Table 2 Standard values for laboratory tests

\begin{tabular}{cc}
\hline Laboratory test & Standard value \\
\hline Hemoglobin & $12.0-15.2 \mathrm{~g} / \mathrm{dl}$ \\
\hline Platelets & $180-380 \mathrm{gpt} / \mathrm{l}$ \\
\hline Partial Thromboplastin time (PTT) & $24.4-32.4 \mathrm{sec}$ \\
\hline Prothrombin ratio & $70-130 \%$ \\
\hline Base excess & $-2.0-2.0 \mathrm{mmol} / /$ \\
\hline Lactate & $0.5-2.2 \mathrm{mmol} / \mathrm{l}$ \\
\hline
\end{tabular}




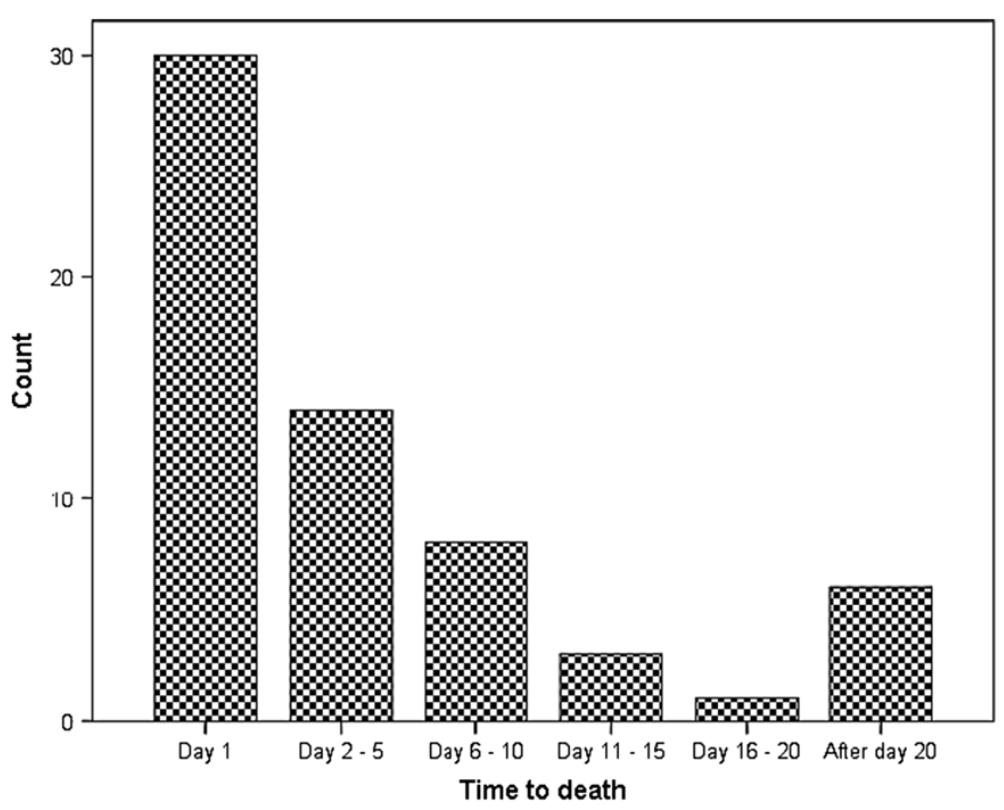

Figure 1 Time to death in severely injured elderly patients.

intervals (CI) were used to determine predictors for mortality. The cutoffs for laboratory tests were set according standard values (Table 2).

\section{Statistics}

Data were analyzed using the Statistical Package for the Social Sciences (SPSS21; IBM Company; Chicago, IL, USA). Incidences are represented as percentages. Measured values are represented as means and 95\% CI for continuous variables, and for categorical variables as medians and interquartile ranges (IQR). Differences were evaluated using the Chi-squared test for categorical variables and the $t$-test for continuous variables. When performing the $t$-test, Levene's test was also performed. In cases of variance heterogeneity, the Welch-test was used instead of the $t$-test. Normal distribution was tested using the Kolmogorov-Smirnov-test. When an obvious deviation from normality was detected, continuous variables were tested with a non-parametric rank test (Mann-Whitney test). Differences were considered statistically significant when $\mathrm{p}<0.05$.

\section{Results}

\section{General results}

In the observation period, 2,304 patients were admitted to the trauma room. Of these, 258 patients were aged more than 75 years. A total of 108 patients met the inclusion criteria, of which $38.3 \%$ were male.

The median GCS was 6 (3-13), the median ISS was 25 (20-29), the median AIS head was 5 (4-5), and the mean age was 82.2 years. 62 patients died after trauma, resulting in a mortality proportion of $57.4 \%$. The expected mortality proportion, demonstrated by the RISC, was $54.6 \%$. Most of the patients $(29 ; 46.8 \%)$ died within the first 24 hours (Figure 1). In addition, 15 (24.2\%) died between days 2 and 5, 8 (12.9\%) between days 6 and 10, and $10(16.1 \%)$ after day 10 . The in-hospital mortality was analyzed.

The primary cause of death was severe head injury, claiming 37 (59.7\%) patients by traumatic brain injury. In

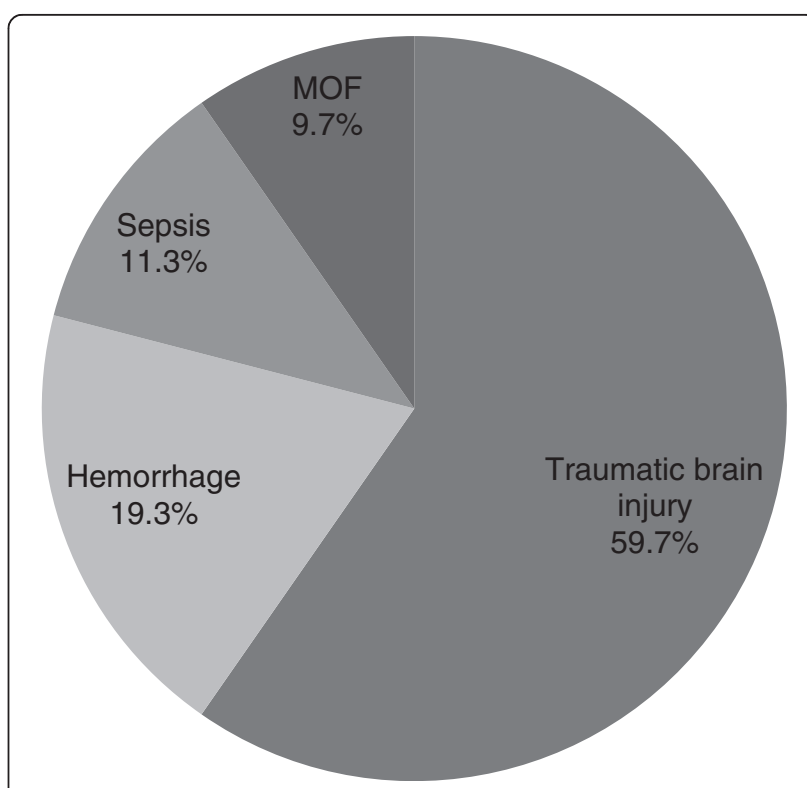

Figure 2 Cause of death in severely injured elderly patients. 
addition, $12(29.4 \%)$ patients died as a result of hemorrhage, $7(11.3 \%)$ as a result of sepsis, and $6(9.7 \%)$ as a result of MOF (Figure 2).

\section{Comparisons between decedents and survivors}

Differences between survivors and decedents are shown in Table 3.

The decedents were more severely injured, having a higher ISS (26 vs. 20, p < 0.001) (Figure 3) compared to survivors. Decedents suffered more severe head trauma, evidenced by a lower GCS ( 4 vs. 12, p < 0.001), and the higher AIS head score ( 5 vs. $4, \mathrm{p}=0.006$ ). No differences were found in other the AIS scores.

There was no statistical difference in the ASA score, suggesting the two groups were similar regarding comorbid conditions. There were also no differences in the physiologic parameters, such as systolic blood pressure, heart rate, or oxygen saturation, whether at the accident scene or in the trauma room.

The first hemoglobin count was different between the groups, with lower values in the decedents (10.5 vs. $11.6 \mathrm{~g} / \mathrm{dl}, \mathrm{p}=0.004)$. The coagulation values were different as well. The PTT was extended to 41.1 seconds in decedents compared to 27.6 seconds in survivors $(\mathrm{p}=$ $0.008)$. Prothrombin ratio was lower in the decedents $(66.5 \%$ vs. $82.8 \%, p=0.016)$. No difference was found in platelet counts.

Although the base excess was not different between the two groups, the lactate value was higher in the decedents than in survivors ( 2.9 vs. $1.6 \mathrm{mmol} / \mathrm{l}, \mathrm{p}=0.043)$.

Table 3 Differences between survivors and decedents

\begin{tabular}{|c|c|c|c|}
\hline & Decedents & Survivors & $\mathrm{p}$ value \\
\hline GCS & $4(3-9)$ & $12(6-15)$ & $<0.001^{*}$ \\
\hline RTS & $5.2(4.5-5.9)$ & $6.6(5.8-7.3)$ & $=0.003^{*}$ \\
\hline ISS & $26(25-33)$ & $20(17-25)$ & $<0.001^{*}$ \\
\hline TRISS & $0.4(0.3-0.6)$ & $0.8(\mathrm{Cl} 0.7-0.9)$ & $<0.001^{*}$ \\
\hline RISC & $69.6(63.4-75.9)$ & $34.5(27.0-42.1)$ & $<0.001^{*}$ \\
\hline AIS Head & $5(4-5)$ & $4(3-4)$ & $=0.006^{*}$ \\
\hline$\overline{\mathrm{ASA}}$ & $2(2-2)$ & $2(2-2)$ & $=0.325$ \\
\hline Age & $81.9(80.7-83.2)$ & $82.6(81.1-84.2)$ & $=0.511$ \\
\hline SBR AS & $140(100-160)$ & $140(120-160)$ & $=0.381$ \\
\hline Heart rate AS & $88(80-100)$ & $88(80-100)$ & $=0.839$ \\
\hline Oxygen saturation AS (\%) & $90(80-96)$ & $93(89-96)$ & $=0.117$ \\
\hline SBP TR & $125(93-152)$ & $142(113-161)$ & $=0.070$ \\
\hline Heart rate TR & $87(70-107)$ & $87(76-100)$ & $=0.804$ \\
\hline Oxygen saturation TR (\%) & $99(96-100)$ & $98(95-100)$ & $=0.396$ \\
\hline $\mathrm{Hb}(\mathrm{g} / \mathrm{dl})$ & $10.5(9.9-11.1)$ & $11.6(11.0-12.3)$ & $=0.004^{*}$ \\
\hline PTT (sec.) & $41.1(30.0-52.3)$ & $27.6(24.4-30.8)$ & $=0.008^{*}$ \\
\hline Prothrombin ratio (\%) & $66.5(57.3-75.6)$ & $82.8(73.9-91.8)$ & $=0.016^{*}$ \\
\hline Base excess & $-4.6(-6.3--3.0)$ & $-2.7(-4.5-1.0)$ & $=0.129$ \\
\hline Lactate $(\mathrm{mmol} / \mathrm{l})$ & $2.9(1.8-3.9)$ & $1.6(1.1-2.0)$ & $=0.043^{*}$ \\
\hline ICU stay (days) & $6.5(3.6-9.5)$ & $15.6(10.0-21.1)$ & $<0.001^{*}$ \\
\hline Hospital stay (days) & $7.5(4.4-10.6)$ & $20.2(14.9-25.5)$ & $<0.001^{*}$ \\
\hline Pre-hospital volume (ml) & $875.0(698.1-1051.9)$ & $869.6(665.1-1074.1)$ & $=0.982$ \\
\hline TR volume $(\mathrm{ml})$ & $1506.6(1153.2-1860.0)$ & $1283.4(876.9-1690.0)$ & $=0.252$ \\
\hline Total volume (ml) & $2439.7(1966.4-2913.1)$ & $2215.5(1613.8-2817,2)$ & $=0.321$ \\
\hline Time in TR (min) & $51.9(45.8-58.0)$ & $54.7(46.9-62.4)$ & $=0.710$ \\
\hline Gender Male & $37.1 \%$ & $40 \%$ & $=0.760$ \\
\hline Rate of whole-body CT & $53.6 \%$ & $56.8 \%$ & $=0.763$ \\
\hline MOF & $51 \%$ & $23.3 \%$ & $=0.006^{*}$ \\
\hline Sepsis & $15.8 \%$ & $25.0 \%$ & $=0.249$ \\
\hline Intubation at AS & $77.4 \%$ & $40 \%$ & $<0.001^{*}$ \\
\hline Intubation in TR & $40.7 \%$ & $43.5 \%$ & $=0.773$ \\
\hline
\end{tabular}

Categorical variables are presented as median with the interquartile range in parentheses, continuous variables as means with the $95 \%$ confidence interval in parentheses, and incidences as percentages; *significant differences. 


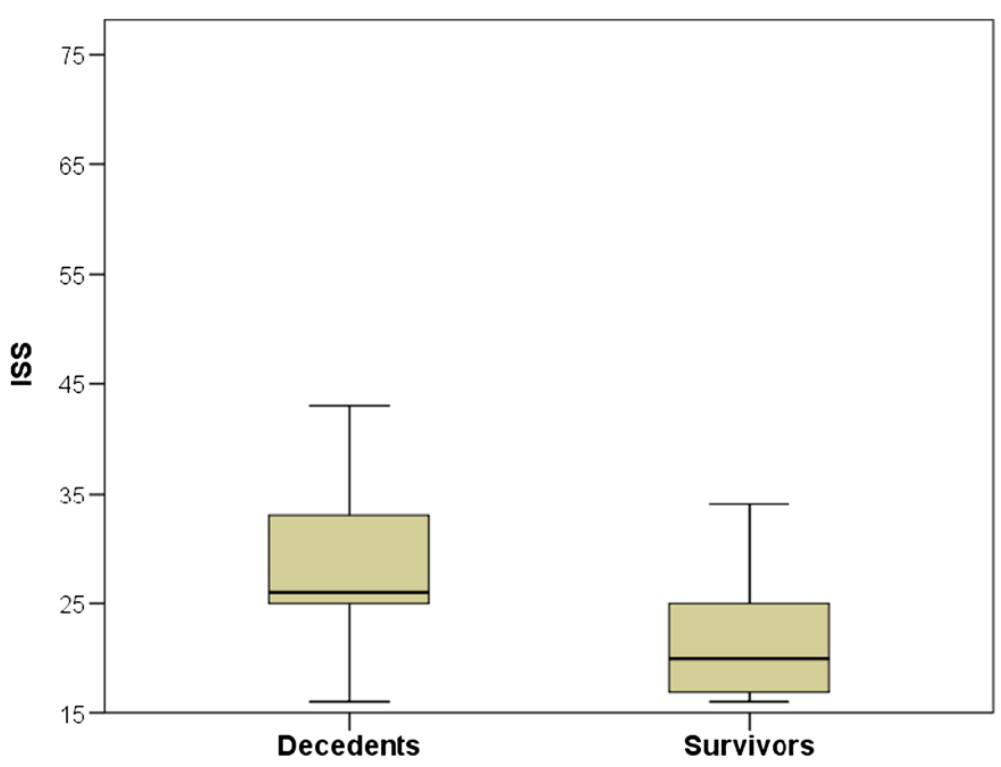

Figure 3 Box-plot diagram of the ISS divided into decedents and survivors.

The lengths of stay in the ICU and in hospital were shorter in the decedents. All other investigated time periods were not different.

No differences were found in the fluid volumes the patients received. In total, decedents received $2439.7 \mathrm{ml}$ and the survivors received $2215.5 \mathrm{ml}(\mathrm{p}=0.321) .52 \mathrm{pa}$ tients received more than $1500 \mathrm{ml}$ fluid volume. Of these, 23 presented normal physiologic parameters at the accident scene and in the trauma room (systolic blood pressure $\geq 120 \mathrm{~mm} \mathrm{Hg}$, pulse rate $<100 \mathrm{bpm}$ ). The blood pressure cutoff of $120 \mathrm{~mm} \mathrm{Hg}$ was used, because no emergency physician might consider such a blood pressure as hemorrhage-inducted hypotension. The distribution of infused fluid volumes is presented in Figure 4.
Decedents suffered from MOF more often (51\% vs. 23.3\%). Analysis by organ system resulted in a higher proportion of failure in decedents in almost every system, respiratory $(56.1 \%$ vs. $23.3 \%$; $\mathrm{p}=0.001)$, central nervous system $(86.4 \%$ vs. $43.5 \% ; \mathrm{p}<0.001)$, heart and circulatory system $(71.2 \%$ vs. $18.6 \% ; \mathrm{p}<0.001)$, and renal system $(22 \%$ vs. $4.8 \% ; \mathrm{p}=0.018)$. Failure rate in only the hepatic system was not different between the groups.

The results of determining odds ratios and relative risks are shown in Table 4. Six predictors for mortality in elderly trauma patients were identified: ISS $>25$, GCS $<9$, PTT $>32.4$ seconds, prothrombin ratio $<70 \%$, AIS head $>$ 3 , and $\mathrm{Hb}<12 \mathrm{~g} / \mathrm{dl}$. The strongest predictor for mortality was ISS $>25$, with a 7 -fold higher risk for a fatal course.

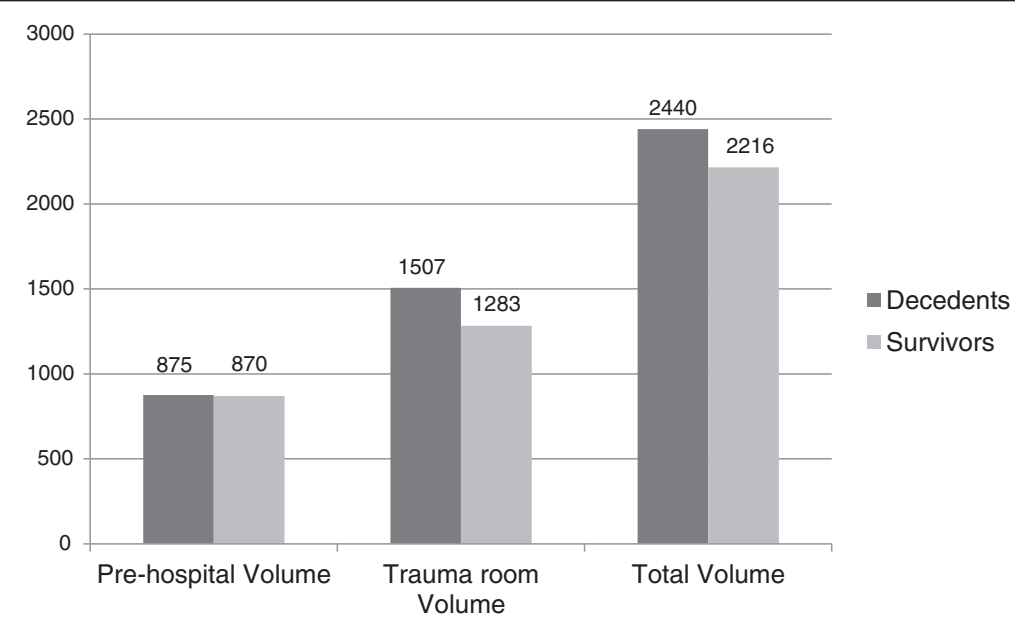

Figure 4 Distribution of the infused fluid volume divided by decedents and survivors. 
Table 4 Odds ratios and relative risk of the differences between decedents and survivors

\begin{tabular}{llll}
\hline Variable & Odds ratio $(\mathbf{9 5} \% \mathbf{C l})$ & Relative risk (95\% Cl) & p value \\
\hline ISS $>\mathbf{2 5}$ & $6.77(2.62-17.45)$ & $3.60(1.76-7.40)$ & $<0.001$ \\
\hline GCS $<\mathbf{9}$ & $4.53(1.97-10.40)$ & $1.98(1.30-3.02)$ & $<0.001$ \\
\hline AIS Head $>\mathbf{3}$ & $2.77(1.12-6.88)$ & $1.29(1.01-1.63)$ & $=0.025$ \\
\hline $\mathbf{H b}<\mathbf{1 2} \mathbf{~ g / d l}$ & $2.65(1.19-5.91)$ & $1.45(1.05-2.01)$ & $=0.016$ \\
\hline PTT $>\mathbf{3 2 . 4} \mathbf{~ s e c ~}$ & $3.62(1.13-11.57)$ & $2.67(1.06-6.73)$ & $=0.025$ \\
\hline $\begin{array}{l}\text { Prothrombin } \\
\text { ratio }<\mathbf{7 0} \%\end{array}$ & $2.39(1.02-5.55)$ & $1.69(1.00-2.88)$ & $=0.042$ \\
\hline $\begin{array}{l}\text { Lactate } \\
>\mathbf{2 . 2} \mathbf{~ m m o l} / \mathbf{l}\end{array}$ & $2.07(0.59-7.29)$ & $1.65(0.68-4.03)$ & $=0.253$ \\
\hline
\end{tabular}

ISS, Injury Severity Score; GCS, Glasgow Coma Scale; AIS Abbreviated Injury Scale; Hb, Hemoglobin; PT, Partial Thromboplastin time.

Table 5 Cause of injury

\begin{tabular}{ccccr}
\hline Cause of injury & Total & Decedents & Survivors & p value \\
\hline Traffic accident, car & $3.7 \%$ & $4.8 \%$ & $2.2 \%$ & $=0.478$ \\
\hline Traffic accident, motorcycle & $1.9 \%$ & $1.6 \%$ & $2.2 \%$ & $=0.831$ \\
\hline Traffic accident, bicycle & $3.7 \%$ & $3.2 \%$ & $4.4 \%$ & $=0.760$ \\
\hline Traffic accident, pedestrian & $22.2 \%$ & $21 \%$ & $23.8 \%$ & $=0.716$ \\
\hline Fall $>\mathbf{3 m}$ & $10.2 \%$ & $12.9 \%$ & $6.5 \%$ & $=0.557$ \\
\hline Fall $<3 \mathbf{m}$ & $51.9 \%$ & $50 \%$ & $54.4 \%$ & $=0.618$ \\
\hline Others & $6.4 \%$ & $6.5 \%$ & $6.5 \%$ & $=0.577$ \\
\hline
\end{tabular}

The total number of cases and proportion of cases in decedents and survivors are shown.

The most common cause of trauma was fall from a height less than $3 \mathrm{~m}$ (for decedents and survivors), followed by accidents as a pedestrian. No differences occurred between decedents and survivors according the cause of trauma (Table 5).

\section{Age-adjusted analysis}

The mortality proportion was similar in all age-adjusted groups with no great difference to the prognostic mortality proportion, as reported by the RISC-score (Figure 5). In all age-groups, the observed and expected mortality rate was $50 \%$ or greater.

The preclinical intubation proportion was different between survivors and decedents. Most decedents were intubated at the accident scene. This difference was found in all age-groups.

Looking at the group of patients aged less than 86 years, survivors had a significantly higher GCS. Only in the

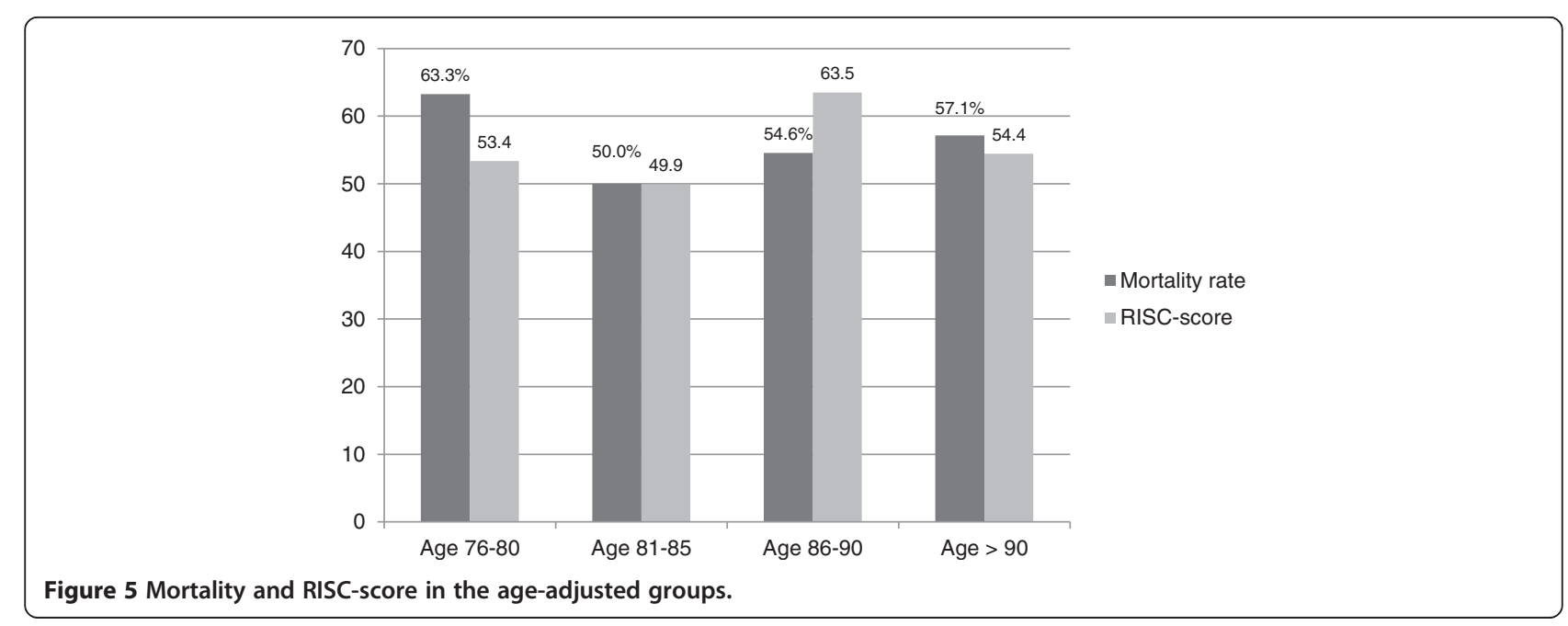


Table 6 Significant differences in decedents and survivors divided by age

\begin{tabular}{|c|c|c|c|c|}
\hline Age & & Decedents & Survivors & $\mathrm{p}$ value \\
\hline \multirow[t]{10}{*}{$76-80$} & Patients & 31 & 18 & \\
\hline & GCS & $6(3-12)$ & $14(9-15)$ & $=0.004$ \\
\hline & ISS & $26(25-33)$ & $20(17-25)$ & $<0.001$ \\
\hline & TRISS & $0.5(0.4-0.6)$ & $0.8(0.6-1.0)$ & $=0.001$ \\
\hline & RISC & $68.6(59.2-78.1)$ & $27.9(17.8-38.0)$ & $<0.001$ \\
\hline & Intubation at AS & $71 \%$ & $35.3 \%$ & $=0.017$ \\
\hline & Thoracic drainage in TR & $21.4 \%$ & $0 \%$ & $=0.035$ \\
\hline & MOF & $56 \%$ & $25 \%$ & $=0.050$ \\
\hline & Mortality proportion & & & \\
\hline & RISC overall & & & \\
\hline \multirow[t]{12}{*}{$81-85$} & Patients & 15 & 15 & \\
\hline & GCS & $3(3-8)$ & $13(6-15)$ & $=0.002$ \\
\hline & RTS & $4.5(2.8-6.1)$ & $7.1(6.4-7.8)$ & $=0.003$ \\
\hline & ISS & $26(25-36)$ & $19(17-25)$ & $=0.007$ \\
\hline & TRISS & $0.4(0.2-0.6)$ & $0.9(0.8-1.0)$ & $<0.001$ \\
\hline & RISC & $69.3(54.2-84.4)$ & $30.5(15.1-45.8)$ & $<0.001$ \\
\hline & Heart rate at AS & $100(90-120)$ & $80(76-84)$ & $=0.015$ \\
\hline & Heart rate in TR & $112(80-123)$ & $82(76-100)$ & $=0.037$ \\
\hline & PTT (sec) & $56.4(13.0-99.9)$ & $29.6(22.9-36.2)$ & $=0.008$ \\
\hline & Intubation at AS & $73.3 \%$ & $33.3 \%$ & $=0.028$ \\
\hline & Mortality proportion & & & \\
\hline & RISC overall & & & \\
\hline \multirow[t]{6}{*}{$86-90$} & Patients & 12 & 10 & \\
\hline & ISS & $26(25-29)$ & $24(17-25)$ & $=0.007$ \\
\hline & RISC & $74.4(64.5-84.4)$ & $50.4(32.3-68.5)$ & $=0.030$ \\
\hline & Intubation at AS & $100 \%$ & $70 \%$ & $=0.041$ \\
\hline & Mortality proportion & & & \\
\hline & RISC overall & & & \\
\hline \multirow[t]{4}{*}{$>90$} & Patients & 4 & 3 & \\
\hline & Intubation at AS & $75 \%$ & $0 \%$ & 0.047 \\
\hline & Mortality proportion & & & \\
\hline & RISC overall & & & \\
\hline
\end{tabular}

Categorical variables are presented as median with the interquartile range in parentheses, continuous variables as means with the $95 \%$ confidence interval in parentheses, and incidences as percentages; GCS, Glasgow Coma Scale; ISS, Injury Severity Score; TRISS, Trauma and Injury Severity Score; RISC, Revised Injury Severity Classification; AS, Accident scene; TR, Trauma room; MOF, Multi-organ failure; PTT, Partial Thromboplastin time.

youngest group (76-80 years of age) did the decedents suffer more MOF than the survivors. In older patients, no difference in MOF and sepsis proportion occurred between decedents and survivors. There were no differences in AIS scores between groups (Table 6).

\section{ISS-adjusted analysis}

The ISS-adjusted analysis, presented in Table 7, showed differences between decedents and survivors only in those scoring 16-25. Only 10 patients presented an ISS > 45 (Table 7).

The surviving-proportion was only $17.1 \%$ among patients presenting an ISS $>25$. The ISS-adjusted mortality proportion and the expected mortality proportion are shown in Figure 6.

In the ISS 16-25 group, decedents suffered more severe head injury than survivors, evidenced by lower GCS and significantly higher AIS score head. Also, decedents had deranged coagulation with significantly lower prothrombin ratio and a prolonged PTT, compared to survivors.

\section{Discussion}

Predicted demographic change will result in trauma physicians being faced with a higher rate of elderly trauma patients. This study focused on severely injured patients aged greater than 75 years. 
Table 7 Significant differences between decedents and survivors divided by ISS

\begin{tabular}{|c|c|c|c|c|}
\hline ISS & & Decedents & Survivors & $\mathrm{p}$ value \\
\hline \multirow[t]{12}{*}{$16-25$} & Patients & 28 & 39 & \\
\hline & GCS & $5(3-10)$ & $12(9-15)$ & $=0.002$ \\
\hline & RTS & $5.4(4.3-6.6)$ & $6.7(5.9-7.4)$ & $=0.028$ \\
\hline & ISS & $25(25-25)$ & $18(17-24)$ & $<0.001$ \\
\hline & TRISS & $0.5(0.4-0.7)$ & $0.8(0.7-0.9)$ & $=0,003$ \\
\hline & RISC & $63.7(54.5-73.0)$ & $31.4(23.4-39.4)$ & $<0.001$ \\
\hline & PTT (sec) & $43.6(24.1-63.0)$ & $27.2(23.7-30.8)$ & $=0.012$ \\
\hline & Prothrombin value (\%) & $59.1(46.7-71.5)$ & $82.9(72.7-93.1)$ & $=0.004$ \\
\hline & AIS head & $5(4-5)$ & $4(3-4)$ & $=0.006$ \\
\hline & Intubation at AS & $78.6 \%$ & $36.8 \%$ & $=0.001$ \\
\hline & Mortality proportion & & & \\
\hline & RISC overall & & & \\
\hline \multirow[t]{6}{*}{$26-35$} & Patients & 20 & 3 & \\
\hline & GCS & $6(3-8)$ & $14(13-14)$ & $=0.003$ \\
\hline & AIS Thorax & $0(0-2)$ & $3(2-3)$ & $=0.042$ \\
\hline & Male & $25 \%$ & $100 \%$ & $=0.030$ \\
\hline & Mortality proportion & & & \\
\hline & RISC overall & & & \\
\hline \multirow[t]{3}{*}{$36-45$} & Patients & 5 & 3 & \\
\hline & Mortality proportion & & & \\
\hline & RISC overall & & & \\
\hline \multirow[t]{3}{*}{$>45$} & Patients & 9 & 1 & \\
\hline & Mortality proportion & & & \\
\hline & RISC overall & & & \\
\hline
\end{tabular}

Categorical variables are presented as median with the interquartile range in parentheses, continuous variables as means with the $95 \%$ confidence interval in parentheses, and incidences as percentages; GCS, Glasgow Coma Scale; RTS, Revised Trauma Score; ISS, Injury Severity Score; TRISS, Trauma and Injury Severity Score; RISC, Revised Injury Severity Classification; PTT, Partial Thromboplastin time; AS, Accident scene; AIS, Abbreviated Injury Scale.

In this study, the overall mortality proportion was $57.4 \%$. In the same time period, the mortality proportion of all treated severely injured patients in the same hospital was $28.7 \%$ [17]. When patients aged more than 75 years were excluded, the mortality proportion was
$24.9 \%$. This result in a 2 -fold increase of mortality proportion, which is less than previously reported [2].

Similar to Taylor et al. we found greater mortality associated with a higher ISS [5]. Only $17.1 \%$ of the patients who presented with an ISS greater than 25 survived. The

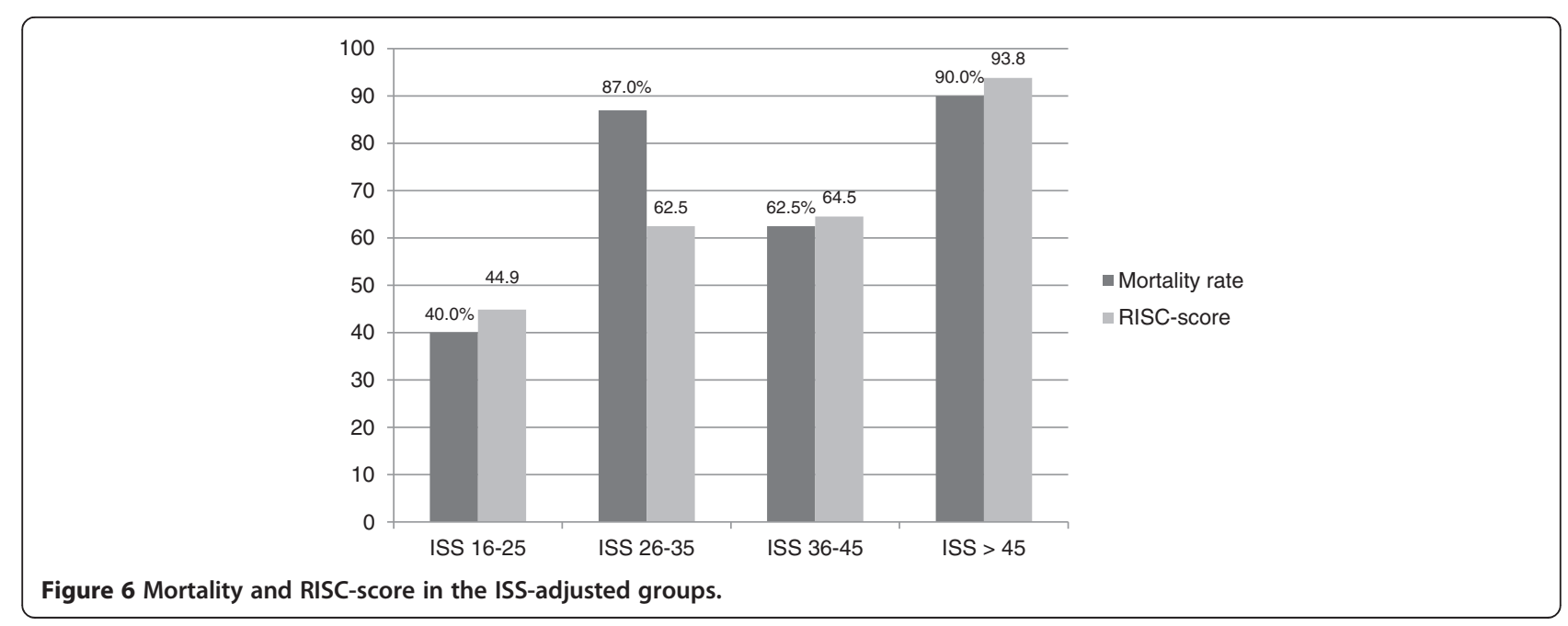


median ISS of survivors and decedents were 20 and 26, respectively. Richmond et al. reported that when ISS was greater than 25 , the odds for a fatal course was raised by a factor of 25 [18]. Our analysis yielded an increase by a factor 7, showing that ISS was the strongest predictor for mortality.

Among AIS scores, we identified the AIS head score as the only one that differed between decedents and survivors. Therefore, it would seem that the decedents suffered more severe head injuries, and that the head injuries are the determinant injuries.

The decedents typically had deranged coagulation when arriving at the trauma room. The mean PTT was prolonged to 41.1 seconds and the mean prothrombin ratio was reduced to $66.5 \%$. One possible explanation is that a severe head injury caused a coagulopathy because of expression of tissue thromboplastin and tissue factor from the injured brain [19-21]. Another explanation could be that elderly patients are more likely to be taking anticoagulant medication. However, this could not be confirmed in our data.

In 23 patients, the heart rate and systolic blood pressure were in the physiologic range at the accident scene and in the trauma room; however, they received over $1500 \mathrm{ml}$ fluid volume in total. According to the S3 guideline of the DGU, patients with a normal systolic blood pressure should not receive fluid volume [22]. Also, Ley et al. reported a higher mortality rate in elderly patients who received more than $1500 \mathrm{ml}$ [23]. We did not find this to be the case, because both the decedents and the survivors received more than $2000 \mathrm{ml}$ volume. Therefore, it might be possible that the mortality proportion would have been lower if less volume had been infused.

In a recently published study, Salottolo et al. reported that lactate is a predictor of mortality in elderly patients [24]. In our study, there was a significantly higher lactate value in decedents than survivors, supporting the idea that lactate might be a predictor for mortality. However, the odds ratios showed that lactate was not an independent predictor for mortality. Salottolo used $2.5 \mathrm{mM}$ as the cut-off, while we used the standard value cut-off (Table 2).

Interestingly, only $38.3 \%$ of the patients were male. In an analysis of trauma patients without limitations to age, the proportion of male patients is greater than twothirds. In the patient group this study is based on the proportion was $71.1 \%$ [17]. In 2010, the life expectancy in Germany for males was 77.3 years, compared to 82.5 years for females. Therefore, it is to be expected that among people aged more than 75 years, the proportion of females is higher. This might also be an explanation for the relatively low proportion of sepsis in the decedents, because studies investigating gender differences report lower sepsis rates among females than males [25-27].
Analyses of the causes of accidents found that most were of low impact, such as a fall from less than $3 \mathrm{~m}$. The second most frequent cause was a traffic accident as a pedestrian. These findings are similar to other recently published studies $[7,28,29]$.

When analyzing mortality in subgroups by age, no differences were found between groups, suggesting that age greater than 75 years is not a predictor for mortality.

In our analysis, we identified six predictors for mortality in elderly trauma patients: ISS $>25$, GCS $<9$, PTT $>$ 32.4 seconds, prothrombin ratio $<70 \%$, AIS head $>3$, and $\mathrm{Hb}<12 \mathrm{~g} / \mathrm{dl}$.

\section{Limitations}

This study is limited because it is a retrospective analysis. Also, as a single-center study, there might be selection for patients treated in our hospital. To confirm these results, a trauma registry analysis with multicenter data should be performed. No statement can be made about patients who died at the accident scene or on the way into hospital because no documentation is available for these patients. This might introduce a bias, although this study investigated only the in-hospital mortality.

\section{Conclusion}

Our findings suggest that the treatment of severely injured elderly patients is a challenging one. Due to predicted demographic changes this group of patients is expected to become increasingly important. The determinant injuries were head injuries and it appears that deranged coagulopathy is an important predictor for mortality. Therefore, rapid normalization of coagulation and, if possible, establishing a medical history of anticoagulant medication use might be important in elderly trauma patients.

\section{Abbreviations \\ AIS: Abbreviated injury scale; AS: Accident scene; ASA: American Society of Anesthesiologists; CCT: Cranial computed tomography; Cl: Confidence interval; DGU: German Society for Trauma Surgery; GCS: Glasgow coma scale; Hb: Hemoglobin; ICU: Intensive care unit; IQR: Interquartile range; ISS: Injury severity score; MOF: Multi-organ failure; PTT: Partial Thromboplastin time; RISC: Revised injury severity classification; ROC: Receiver operating characteristic; RTS: Revised trauma score; SBP: Systolic blood pressure; SPSS: Statistical Package for the Social Sciences; TR: Trauma room; TRISS: Trauma and injury severity score; vs.: Versus.}

\section{Competing interests}

The authors declare that they have no competing interests.

\section{Authors' contributions}

CS and SL designed this study. CS, TP, MS, AW and BH collected and analyzed the data. CS drafted the manuscript, and all authors contributed substantially to its revision. CS takes responsibility for the paper as a whole. All authors read and approved the final manuscript for publication.

\section{Acknowledgements}

A professional language editing service, American Manuscript Editors, was commissioned with the correction of grammar, spelling and other errors. 


\section{Author details}

'Department of Trauma Surgery, University Hospital Essen, University Duisburg-Essen, Hufelandstraße 55, Essen 45147, Germany. ${ }^{2}$ Department of Trauma, Orthopedic, and Hand Surgery, Municial Hospital Neuss,

Lukashospital GmbH, Preußenstraße 84, Neuss 41464, Germany.

Received: 2 May 2014 Accepted: 28 July 2014

Published: 8 August 2014

\section{References}

1. Bevölkerung - Alter im Wandel - Ältere Menschen in Deutschland und der EU - Statistisches Bundesamt (Destatis). https://www.destatis.de/DE/ Publikationen/Thematisch/Bevoelkerung/Bevoelkerungsstand/Alterim Wandel.html] Accessed April 2014

2. Sampalis JS, Nathanson R, Vaillancourt J, Nikolis A, Liberman M, Angelopoulos J, Krassakopoulos N, Longo N, Psaradellis E: Assessment of mortality in older trauma patients sustaining injuries from falls or motor vehicle collisions treated in regional level I trauma centers. Ann Surg 2009, 249:488-495.

3. Goodmanson NW, Rosengart MR, Barnato AE, Sperry JL, Peitzman AB, Marshall GT: Defining geriatric trauma: When does age make a difference? Surgery 2012, 152:668-675.

4. Shifflette VK, Lorenzo M, Mangram AJ, Truitt MS, Amos JD, Dunn EL: Should age be a factor to change from a level II to a level I trauma activation? J Trauma 2010, 69:88-92.

5. Taylor MD, Tracy JK, Meyer W, Pasquale M, Napolitano LM: Trauma in the elderly: intensive care unit resource use and outcome. J Trauma 2002, 53:407-414.

6. Newell MA, Rotondo MF, Toschlog EA, Waibel BH, Sagraves SG, Schenarts PJ, Bard MR, Goettler CE: The elderly trauma patient: an investment for the future? J Trauma 2009, 67:337-340.

7. Dinh MM, Roncal S, Byrne CM, Petchell J: Growing trend in older patients with severe injuries: mortality and mechanisms of injury between 1991 and 2010 at an inner city major trauma centre. ANZ J Surg 2013, 83:65-69.

8. Scalea TM, Simon HM, Duncan AO, Atweh NA, Sclafani SJ, Phillips TF, Shaftan GW: Geriatric blunt multiple trauma: improved survival with early invasive monitoring. J Trauma 1990, 30:129-134. discussion 134-6.

9. Victorino GP, Chong TJ, Pal JD: Trauma in the elderly patient. Arch Surg 2003, 138:1093-1098.

10. Lehmann R, Beekley A, Casey L, Salim A, Martin M: The impact of advanced age on trauma triage decisions and outcomes: a statewide analysis. Am J Surg 2009, 197:571-574. discussion 574-5.

11. Martin JT, Alkhoury F, O'Connor JA, Kyriakides TC, Bonadies JA: 'Normal' vital signs belie occult hypoperfusion in geriatric trauma patients. Am Surg 2010, 76:65-69.

12. Baker SP, O'Neill B, Haddon W, Long WB: The injury severity score: a method for describing patients with multiple injuries and evaluating emergency care. J Trauma 1974, 14:187-196.

13. Osler T, Baker SP, Long W: A modification of the injury severity score that both improves accuracy and simplifies scoring. J Trauma 1997, 43:922-925. discussion 925-6.

14. Teasdale $G$, Jennett $B$ : Assessment of coma and impaired consciousness. A practical scale. Lancet 1974, 2:81-84.

15. Champion HR, Sacco WJ, Carnazzo AJ, Copes W, Fouty WJ: Trauma score. Crit Care Med 1981, 9:672-676.

16. Lefering R: Development and validation of the revised injury severity classification score for severely injured patients. Eur J Trauma Emerg Surg 2009, 35:437-447.

17. Schoeneberg C, Schilling M, Keitel J, Kauther MD, Burggraf M, Hussmann B, Lendemans S: TraumaNetwork, Trauma Registry of the DGU(R), Whitebook, S3 Guideline on Treatment of Polytrauma/Severe Injuries An Approach for Validation by a Retrospective Analysis of 2304 Patients (2002-2011) of a Level 1 Trauma Centre. Zentralb/ Chir 2014, Epub ahead of print.

18. Richmond TS, Kauder D, Strumpf N, Meredith T: Characteristics and outcomes of serious traumatic injury in older adults. J Am Geriatr SoC 2002, 50:215-222.

19. Pathak A, Dutta S, Marwaha N, Singh D, Varma N, Mathuriya SN: Change in tissue thromboplastin content of brain following trauma. Neurol India 2005, 53:178-182.
20. Joseph B, Aziz H, Zangbar B, Kulvatunyou N, Pandit V, O'Keeffe T, Tang A, Wynne J, Friese RS, Rhee P: Acquired coagulopathy of traumatic brain injury defined by routine laboratory tests: which laboratory values matter? J Trauma Acute Care Surg 2014, 76:121-125.

21. Carrick MM, Tyroch AH, Youens CA, Handley T: Subsequent development of thrombocytopenia and coagulopathy in moderate and severe head injury: support for serial laboratory examination. J Trauma 2005, 58:725-729. discussion 729-30.

22. German Trauma Society (DGU): S3 - guideline on treatment of patients with severe and Multiple Injuries. http://www.awmf.org/fileadmin/ user_upload/Leitlinien/012_D_Ges_fuer_Unfallchirurgie/012-019e_S3 Severe_and_Multiple_Injuries_2012-11.pdf Accessed April 2014.

23. Ley EJ, Clond MA, Srour MK, Barnajian M, Mirocha J, Margulies DR, Salim A: Emergency Department Crystalloid Resuscitation of $1.5 \mathrm{~L}$ or more is Associated with increased mortality in elderly and nonelderly trauma patients. J Trauma 2011, 70:398-400.

24. Salottolo KM, Mains CW, Offner PJ, Bourg PW, Bar-Or D: A retrospective analysis of geriatric trauma patients: venous lactate is a better predictor of mortality than traditional vital signs. Scand J Trauma Resusc Emerg Med 2013, 21:7.

25. Majetschak M, Christensen B, Obertacke U, Waydhas C, Schindler AE, Nast-Kolb D, Schade FU: Sex differences in posttraumatic cytokine release of endotoxin-stimulated whole blood: relationship to the development of severe sepsis. J Trauma 2000, 48:832-839. discussion 839-40.

26. Schoeneberg C, Kauther MD, Hussmann B, Keitel J, Schmitz D, Lendemans S: Gender-specific differences in severely injured patients between 2002 and 2011: data analysis with matched-pair analysis. Crit Care 2013, 17:R277

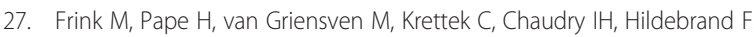
Influence of sex and age on mods and cytokines after multiple injuries. Shock 2007, 27:151-156.

28. Schönenberger A, Billeter AT, Seifert B, Neuhaus V, Trentz O, Turina M: Opportunities for improved trauma care of the elderly - A single center analysis of 2090 severely injured patients. Arch Gerontol Geriatr 2012 55:660-666.

29. Giannoudis PV, Harwood PJ, Court-Brown C, Pape HC: Severe and multiple trauma in older patients; incidence and mortality. Injury 2009, 40:362-367.

doi:10.1186/s13049-014-0045-3

Cite this article as: Schoeneberg et al:: Mortality in severely injured elderly patients: a retrospective analysis of a German level 1 trauma center (2002-2011). Scandinavian Journal of Trauma, Resuscitation and Emergency Medicine 2014 22:45

\section{Submit your next manuscript to BioMed Central and take full advantage of:}

- Convenient online submission

- Thorough peer review

- No space constraints or color figure charges

- Immediate publication on acceptance

- Inclusion in PubMed, CAS, Scopus and Google Scholar

- Research which is freely available for redistribution 